\title{
Knowing, Understanding, and Other Forms of Learning
}

\section{Bette LaSere Erickson and Glenn R. Erickson}

\section{Introduction}

Probably the most common verbs in higher education are "to know," "to understand," "to think," and "to appreciate." They sound like pretty good verbs for college classrooms. They call to mind some admired intellectual activities.

However, they are also among the most slippery verbs we use in college classrooms. Consider, for example, what comes to mind when we say we want students "to understand." To some, understanding means being well informed - remembering important facts, events, ideas, theories. To others, understanding involves the ability to explain, to marshal evidence, to detect the unwarranted conclusion. Understanding is used synonymously with remembering, relating, comparing, applying, and a whole host of other intellectual processes.

Blurring the distinctions among these intellectual activities would not be a problem if developing such abilities required the same teaching and learning activities. However, research on learning suggests there are some important differences among abilities - differences which call for different teaching methods and study procedures.

These materials describe four of the more common types of learning outcomes pursued in college courses. They also include some notes on how to formulate questions, write objectives, select teaching methods, and construct test items for each type. Although you may find it necessary to adapt or reshape the categories to fit your subject matter, we think they provide a useful conceptual tool for clarifying 
what you want students to learn and for making instructional decisions.

\section{Memorization}

In most courses, there is some basic information which students are expected to commit to memory. Such information sometimes includes names, definitions, terminology, or other facts. More often in college courses, students are asked to remember more complex information-fundamental laws, theoretical propositions, the characteristics of a period, points of view expressed in their reading.

For instance, the following questions ask students to recall information which was presented during instruction.

What are the distinguishing characteristics of the following approaches to literary analysis: the historical approach; the psychological approach; the thematic approach; the "elements of fiction" approach.

Briefly summarize the procedures, the advantages,and the confounding variables associated with each of the following research designs: crosssectional; longitudinal; time-sequential; and experimental.

Briefly describe the following Piagetian concepts: assimilation; accommodation; concrete operational thinking; formal operational thinking; conservation.

Knowing how an insect feeds can be important in controlling insect damage to crops. What are the characteristics of each of the following types of feeders: generalized feeders; sucking feeders; boring feeders; rasping feeders. What general principles and techniques are suggested in your readings for controlling each type of feeder?

Briefly describe the distinguishing characteristics of each of the following artistic movements: Neo-Classicism; Romanticism; Realism; Impressionism; Post-Impressionism.

Many people - faculty, as well as students - do not recognize that these questions simply ask students to recall information which they've committed to memory. To be sure, they differ from questions which ask students to recall a name or a date or some other isolated bit of information. These questions require students to remember much more complex information. 
However, the distinguishing feature of memorization is NOT its complexity. Rather, this type of learning may be recognized by what we ask students to do with the information: to remember it and be able to recall it.

Memorization does not enjoy a very respectable position in higher education these days. To some extent, its reputation is deserved, since we've not always been sensible or frugal about what we ask students to memorize. Yet, being able to recall basic information is often necessary for further study in a course or in a field. Moreover, recent research on thinking and problem-solving suggests that the knowledge available to students plays a critical role in developing other intellectual skills and being able to transfer them to new problems and situations.

\section{Writing Objectives for Memorization}

It's fairly easy to write objectives which inform students that memorization will be required. However, because we're often embarrassed to tell students and colleagues that we want students to memorize, we camouflage these expectations in language which makes them sound more worthy. We ask students "to become familiar with" or "to understand." To the extent what familiarity and understanding really mean memorization, it's far more helpful "to tell it like it is." The following sample of objectives make it pretty clear that memorization is required.

Be able to describe the typical questions and conventions which characterize the following approaches to literary analysis: the historical approach; the psychological approach; the thematic approach; the elements of fiction approach.

Be able to describe the procedures, the advantages, and the confounding variables for each of the following research designs: cross-sectional; longitudinal; time-sequential; and experimental.

Be able to define the following Piagetian concepts: assimilation, accommodation, conservation, concrete operational thinking, formal operational thinking. 
Be able to recall the characteristics of the major types of feeding systems found in insects and to recall the recommended techniques for controlling each type of feeder.

Be able to recall the distinguishing characteristics of each of the following artistic movements: Neo-Classicism; Romanticism; Realism; Impressionism; Post-Impressionism.

\section{Teaching for Memorization and Retention}

Memorization and retention have been widely researched and much is known about the factors which affect them. The following findings are especially important.

Meaningful material is learned faster and remembered longer than meaningless material. Meaning is a key variable affecting memory and retention; some believe it's the most important variable. However, meaning does not lie in the subject matter; it lies in the relationship between the subject matter and the learner.

Although meaning obviously varies from student to student, we won't go far wrong if we assume that most students find the concrete more meaningful than the abstract; the familiar more meaningful than the unfamiliar; the present more meaningful than the distant past or distant future. That doesn't imply that we should abandon the abstract, the unfamiliar, the past or the future. Learning about such things is why students are in our classes. However, it does suggest that we'll be more successful if we begin instruction with the concrete, the familiar, and the present.

In some subjects, it's relatively easy to point out how material relates to students' current questions and concerns and to draw examples from their experiences. Other subjects require more creativity, and sometimes it seems the only way to make something familiar or concrete is by way of analogy, metaphor, or some other form of poetry.

Practice facilitates memorization and retention. As we'll see, practice is an important condition for all types of learning, although the practice looks different for each type. For memorization and retention, practice takes the forms of recitation, drill, and review. Thus, it helps (1) to provide study questions; (2) to encourage students to quiz themselves and each other after reading an assignment or hearing 
a lecture; (3) to give quizzes; (4) to ask questions in class which require students to verbalize the information which they are to remember.

The rebellion against memorization has discouraged professors from using such instructional techniques in college courses. However, if we wish students to commit material to memory and to remember it for any length of time, recitation and drill and review are sound instructional techniques.

\section{Testing for Memorization}

Writing questions which test memorization merely requires instructors to ask students to recall or recognize material which was presented during instruction. To be sure, many of us could improve our skills in writing such items by attending to some technical properties of test item construction. However, we think the more critical problem is that too few faculty and students distinguish between items which test memorization and items which test other types of learning. Thus, we'd like to raise the red flags on that issue from the beginning.

Consider the English professor who spends a week discussing the "Initiation" themes in the following short stories: "Editha," "The Open Boat," "The Bride Comes to Yellow Sky," and "I Want to Know Why." The professor then includes the following essay questions on the exam.

"Editha," "The Open Boat," "The Bride Comes to Yellow Sky," and "I Want to Know Why" might be thought of as initiation stories in that they dramatize a naive, child-like character going through a difficult, painful, or bewildering experience which initiates him into a view of the world which the reader perceives as more realistic or mature. Discuss any TWO of the above of initiation.

At first glance, this question appears to require some fairly complex analytical skills. However, because the essay asked students to discuss literature which had previously been discussed in class, it's quite possible-indeed, probable-that students memorized the key ideas and appropriate references discussed in class and reproduced them on the exam. 
This situation illustrates a testing practice found in many college courses and in many disciplines. Faculty and students mistakenly assume that if a problem or question calls for an analysis or a solution or a conclusion, then it automatically tests something other than memorization. However, if the question is one which was discussed during instruction, then we're on very shaky ground if we conclude that students are demonstrating anything other than memorization.

\section{Concept Formation}

We all know students who can rattle off definitions of important concepts and terms, who can state fundamental laws and principles, who can describe key theoretical constructs. Many students can even give the definitions, state the laws, and describe the constructs in their own words.

However, if we show these same students a particular example of a concept, many are unable to name the concept it exemplifies. If we present a new situation, they cannot recognize the laws or principles which are operating. If we give them an interpretation or an analysis, they cannot identify the theoretical perspective taken by the interpreter or analyst. And, we begin to worry that students have learned the definitions of concepts, statements of principles, and summaries of theoretical constructs in rote fashion.

One good indicator of comprehension and understanding is Concept Formation-the ability to see relationships between specific instances and broader generalizations. Two kinds of challenges characterize this type of learning: (1) Give the broader generalization and ask students to supply specific examples and illustrations; or (2) Give specific examples or illustrations and ask students for the broader generalization. Because students often respond to the first challenge by supplying examples they've memorized from the text or readings, we recommend the second type of challenge.

The following sample of questions all require the ability to recognize the relationship between a specific instance and some broader generalization.

Attached you'll find a paper analyzing Hawthorne's 'Rappaccini's Daughter." Which approach to literary criticism does it exemplify? 
Professor Wisdom was interested in the effects of age on political attitudes. He used a well-known and widely accepted attitude survey that measures where an individual falls on the conservative-liberal continuum. He asked 100 people of different ages to complete the survey and tabulated the results. He found that older subjects responded more conservatively and concluded that aging is characterized by a progressive increase in conservative attitudes. Professor Wisdom's research design was an example of...a) cross-sectional; b) longitudinal; c) time-sequential; or d) experimental?

While playing with her paints, Sally discovered that blue and yellow make green. However, when her teacher asked her what colors are green, Sally said she didn't know. As soon as Sally is able to recognize that because blue and yellow make green, then green is composed of blue and yellow, Piaget would say she will be demonstrating which of the following? a) conservative; b) formal operational thinking; c) perpetual thinking; d) concrete operational thinking.

A foreign insect which resembles a grasshopper and appears to like spinach has been introduced into the U.S. Entomologists are beginning to worry that the insect will destroy the nation's spinach crops, so they've been studying the insect in the lab. They've determined that the insect is hypognathous. They've alsonoted that it has mandibles, wings, and large head muscles. Based on this information, the insect is probably an example of what type of feeder?

The slide I'm showing you is a reproduction of a painting we've not discussed. Study the painting and decide whether you think it's an example of Neo-Classicism, Romanticism, Realism, Impressionism, or Post-Impressionism. Then explain what characteristic features of the painting led you to your decision.

\section{Writing Objectives for Concept Formation}

Concept formation objectives should somehow capture the key feature of this form of learning: the ability to recognize the relationship between specific instances and their broader generalizations. If the challenges are to be posed as we've recommended, then the objectives should indicate that students (a) will be given specific instances and (b) asked to determine the broader generalization exemplified, illustrated, or represented.

The following statements illustrate some different ways in which such objectives might be phrased. 
Given samples of essays written by literary critics, be able to identify the approach to literary analysis which the critics have taken.

Be able to recognize examples of cross- sectional, longitudinal, timesequential, and experimental designs.

Be able to recognize examples of assimilation, accommodation, concrete operational thinking, formal operational thinking, and conservation.

Whenever you encounter a new insect, you should be able to identify the type of feeding system the insect possesses.

If I show you a painting we've not studied, you should be able to recognize the artistic movement to which it probably belongs.

The most difficult part of communicating Concept Formation objectives to students is getting them to understand that they'll be asked to recognizenew examples and illustrations. Many students mistakenly assume that they'll be asked to recognize examples which were presented in their texts or in class. This leads them to some rather unproductive study behaviors. They write every example in their notes and spend hours memorizing them. Later, they may complain that test questions were not discussed in class.

Thus, it's important that professors stress that this type of learning involves the ability to recognize new examples and illustrations whenever they're encountered. It helps if that information can be included in the objective. Also, since many students pay closest attention when instructors talk in terms of tests, tell students from the start that the examples discussed in class or in the readings will not be the ones which appear on the tests. The test questions will ask them to recognize examples which they've never seen before.

\section{Teaching for Concept Formation}

Fortunately, much is known about how concepts are learned and about the instructional activities which promote Concept Formation. Certainly, more is known than will be discussed here. However, the following suggestions reflect some of the critical conditions for Concept Formation. 
Highlight the critical properties, distinguishing characteristics, or key ideas of the concept, principle, generalization, or theory. These will provide the bases or the criteria for judging whether or not specific instances exemplify or illustrate or represent the broader generalizations. Thus, it's critical that students have complete and accurate information about what "defines" the concept.

Present examples of the concept or principle or generalization or theory, noting in each case how the example embodies the key characteristics. The necessity for providing examples and contrasting them with non-examples is well documented in Concept Formation studies. Fortunately, most instructors know this and take great pains to find especially telling examples and illustrations.

Provide opportunities for students to practice recognizing examples of concepts, illustrations of principles, representations of theories. As noted earlier, PRACTICE is a critical condition for all the forms of learning discussed here. In the case of concept formation, providing practice opportunities requires instructors (a) to pose a series of specific instances; and (b) to ask students the appropriate questions about them: Which concept does this exemplify? Which principle or law or generalization is illustrated in this situation? Which theory or approach does this interpretation reflect? Which theme is being dramatized here? In each case, instructors should ask students to note how the example or situation does or does not embody the critical properties or characteristics of the concept, generalization or theory. The questions included in the introduction to the section on Concept Formation provide some good examples of practice exercises.

Start with relatively simple and clear examples and gradually introduce more complex and subtle examples. The first task is to illustrate the properties, characteristics, features which define the concept or generalization or theory. Students will be able to recognize these more clearly if they don't initially get lost in an illustration which is complicated, abstract, or foreign to them. However, if all the examples are simple ones, students won't learn to recognize more complex ones.

Draw examples and illustrations from a variety of situations and settings. This recommendation is based on studies of transfer of 
learning. Students are more likely to be able to recognize new examples if the examples used during instruction sample the range of situations and contexts in which you want students to be able to recognize the concept, principle, or theory.

Be prepared to provide more practice examples and illustrations than you ever imagined might be necessary. There's no magic number which we can offer as a guide. However, we think most instructors grossly underestimate the number of examples needed and the amount of practice required.

\section{Testing for Concept Formation}

By now, it should come as no surprise that testing for Concept Formation involves (a) presenting a specific instance or situationone that students have not seen before; and (b) asking students which concept it exemplifies, principle it illustrates, theory it reflects, theme it dramatizes. The questions at the beginning of the section on Concept Formation might make good exam questions, assuming they were not discussed during instruction.

At the risk of belaboring the issue, we'd like to stress what does NOT constitute a test of Concept Formation. Questions which ask students to recall or recognize definitions of concepts or statements of principles or summaries of theoretical constructs are not adequate tests of Concept Formation. They can be answered on the basis of memorization.

Similarly, questions which present examples or illustrations which were presented or discussed during instruction are not adequate tests of Concept Formation. Even though the form of the question is appropriate, such questions also may be answered on the basis of memorization.

\section{Application}

It's one thing to be able to define a concept, state a principle, or summarize a theory. It's another thing to recognize examples or illustrations of these things. And, it's yet another to be able to use them to solve problems, perform analyses, make decisions, draw conclusions. 
Application is the ability to use concepts, principles, generalizations, theories and the like to explain or analyze or otherwise cope with specific situations or problems. Most college professors stress the importance of being able to apply previously learned material to a variety of problems and situations. Indeed, many believe that the primary reason for learning such material in the first place is because it's useful in understanding and coping with the situations and problems one encounters in life.

The challenge to apply involves presenting a specific problem or situation and asking students to use what they've learned in some way - to explain the situation, to solve the problem, to predict an outcome, to make a recommendation, to formulate a policy. Application questions usually tell students explicitly or strongly imply which concepts, principles, theories, or generalizations students should use in order to complete the task. (We mention this by way of foreshadowing. It's yet another thing to cope with specific situations without being told which concepts or principles or theories one should use.)

The following questions all ask students to use something they've learned in a specific situation or problem.

A major publishing company has decided to publish a book on Hawthorne's short stories. The publishers plan to devote one whole section of the book to "Rappaccini's Daughter." That section will include several articles, each analyzing the story using a different approach to literary criticism. You've been asked to write the article which analyzes the story using a thematic approach to literary criticism. Outline what you'd say in such an article.

Professor Wisdom was interested in the effects of age on political attitudes. He used a well-known and widely accepted attitude survey that measures where an individual falls on the conservative-liberal continuum. He asked 100 people of different ages to complete the survey and tabulated the results. He found that older subjects responded more conservatively and concluded that aging is characterized by a progressive increase in conservative attitudes. Use your knowledge of the strengths and limitations of cross-sectional research designs to critique Professor Wisdom's conclusions.

Peter, who is mid-way through the first grade, is having a great deal of trouble with subtraction, although he did fairly well with addition. He listens carefully when his teacher explains the material and tries hard 
to do the problems in his workbook. But he just can't seem to get it. Identify one activity which Piaget might recommend to help Peter.

A foreign insect which resembles a grasshopper and appears to like spinach has been introduced into the U.S. The insect is threatening the nation's spinach crops. As an entomologist, you have been hired by a famous sailor from California to combat this pest. Preliminary study revealed that the insect is a generalized feeder. How would you treat the spinach crop to control the pest?

Posted around the room are reproductions of 20 paintings. You have been asked to organize an exhibition designed to capture the spirit of Impressionism. However, space limitations permit you to include only 5 paintings. Which of these paintings would you include in the exhibition? Be prepared to explain why you chose the paintings you chose.

\section{Writing Objectives for Application}

Minimally, application objectives should tell students two things: (1) that they'll be given specific problems or situations; and (2) that they'll be asked to use what they've learned to do something with those problems or situations. At their best, application objectives also say something about the nature of the problems which will be given and alert students to the ways in which they'll be asked to use what they've learned. The following statements illustrate how such objectives might look.

Be able to discuss any American short story, using each of the following approaches to literary analysis: the historical approach, the thematic approach, the psychological approach, the elements of fiction approach.

Given research on the effects of aging, be able to use your knowledge of the strengths and confounding variables associated with cross-sectional, longitudinal, time-sequential, and experimental designs to critique the studies.

Given descriptions of children's responses in instructional situations, be able to use Piagetian constructs to explain their responses and to recommend appropriate instructional activities.

Given information about the feeding systems of insects which are making pests of themselves, be able to recommend procedures for controlling the pests. 
If I show you a collection of paintings, you should be able to organize or critique an exhibit which claims to represent one of the following artistic movements: Neo-Classicism, Romanticism, Realism, Impressionism, Post-Impressionism.

As with Concept Formation objectives, students often misinterpret application objectives to mean that they will be expected to solve the problems or explain the situations or analyze the literature which were discussed in class. Again, it's important to stress that the ability to apply involves coping with a variety of new problems and situations. To put it in terms which students are more likely to understand, test questions will present problems and situations which have not been discussed in class or in the readings.

\section{Teaching for Application}

Before talking about how to teach for application, there's some good news and some bad news. The good news is that lots of research has been done in this area, usually under the rubric "transfer of learning." Many studies have asked essentially the same question: "If students learn how to apply concepts, principles, or theories in one situation, will they be able to apply those concepts, principles, or theories in other situations?

The bad news is that the research findings have not been very encouraging. It appears that not much transfer occurs, even in the best of instructional circumstances. In other words, we can teach students how to apply our subject matter in one situation; but give them a new situation, and they act as if they've never encountered such a problem.

There has, of course, been much speculation and some research into why application skill seem so difficult to develop. While we can't be as confident as we were in discussing Memorization and Concept Formation, we can offer the following suggestions.

Demonstrate how to apply course materials to specific problems or situations. That is, pose a sample problem or situation and show students how you would go about solving it or explaining it or whatever. Highlight key decisions and explain why you did what you did. 
Provide opportunities for students to practice application. Again practice is a critical condition for application. It requires instructors to pose specific problems or situations and to ask students to solve the problems or explain the situations or predict the outcomes or whatever.

Be keenly aware that instructors demonstrating how to apply is not the same as students practicing how to apply. If you solve all the problems or explain all the situations, you'll get lots of practice... but you probably don't need it. Your students probably do.

Pose problems and situations which sample the range of contexts in which you hope students will be able to apply course material. Transfer of learning studies found that when the problems used during instruction differed dramatically from the problems posed to test for transfer, students appeared unable to transfer. However, when instruction sampled the range of contexts in which students were expected to apply, transfer seemed to increase.

Help students recognize similarities in problems and situations. One obstacle to transfer seems to be that students fail to recognize similarities between new problems and those they've already solved successfully. Professors might help students recognize such similarities by asking: What are the "givens" in this situation? What are you asked to do? How is this situation similar to (or different from) other problems you've solved? What concepts and principles did you use in solving those problems? Would they work in this problem or situation?

Plan instruction systematically so that students receive lots of guidance on early attempts to apply and less and less guidance on subsequent attempts. Students often need step-by-step prompts, hints, and feedback when they first encounter problems or situations which require them to use course material in some way. In fact, we recommend that initial practice exercises be done in class where instructors are available for such guidance. In any event, teaching for application is not the time to use the "sink-or-swim" approach. Many students will find it too frustrating, will give up prematurely, and may drown in their sense of failure.

However, students do need to learn to cope with problems or situations on their own. They won't if professors continue to "lead them through" the analyses or the solutions or the critiques. Thus, it's 
important to withdraw gradually the prompts and the hints and the other step-by-step questions.

Provide more practice than you ever dreamed might be required. Again, most of us grossly underestimate the amount of practice which students need. We forget what it's like to be a novice in our fieldshow it felt to encounter a problem the first or second or tenth time.

This means, of course, that teaching for application takes time. It's tempting to short-cut the instructional process and hope for the best. However, instructors who fall prey to such temptations are likely to be disappointed when they test their students' application skills.

\section{Testing for Application}

In order to test students' abilities to apply, instructors must (a) present a specific problem or situation-one that has not been discussed previously; and (b) ask students to use some concept or principle or theory to solve the problem, analyse the situation, predict the outcome, or whatever the appropriate task might be. The examples of questions included in the introduction to application might be good test items, assuming that they were not used during instruction. However, how to write multiple choice items which test application is a topic considered elsewhere.

We'd like to stress here that asking students to recall the definition of a concept, the statement of a principle, or the description of a theoretical construct is NOT an adequate test of whether students can apply the concept, principle, or construct. Such questions on the basis of memorization. The problems and situations posed on exams must be new to students.

Finally, questions which test for application usually state explicitly or strongly imply which concepts, principles, theoretical constructs, or ideas students are to use in dealing with the situation or problem. In part, it's this feature which distinguishes Application from Complex Problem Solving.

\section{Complex Problem Solving}

Complex Problem Solving is the ability to use course material in coping with real life situations and problems. It resembles Application 
in that it involves presenting a particular problem or situation and asking students to do something with it - to perform an analysis, to find a solution, to offer an explanation, to recommend a policy, to reach a decision. Indeed, it may be useful to think of Application and Complex Problem Solving as a continuum rather than as separate categories. However, for purposes of instruction and evaluation, it's helpful to make some distinctions.

Application problems and situations are usually fairly structured and direct about what is to be done. It's clear which features of the problem or situation deserve attention and which concepts and principles are to be used. Thus, an application task states explicitly or strongly implies how to approach and think through the problem or situation. In contrast, Complex Problem Solving tasks and questions permit more flexibility in determining how to approach and think through the problem or situation for several reasons.

First, the problems and situations posed in a Complex Problem Solving question are usually more complicated and less structured. More information is presented, and some of the information may be irrelevant and conflicting. Key ideas and relationships are less obvious and may be embedded in a morass of detail. The task to be accomplished should be clear, but the questions or issues to be considered along the way may not be so obvious. Thus, Complex Problem Solving situations usually demand some restructuring. They may require students to determine what questions to ask or issues to consider, to decide which features of the situation warrant attention, to judge the credibility of sources and resolve conflicts, to take some key elements out of the contexts in which they're presented, to see relationships which are not explicitly stated or immediately obvious.

Secondly, a Complex Problem Solving task does not tell students which concepts, principles, theories, or ideas they should use in coping with the situation. Part of the challenge is to sort through what one has studied and to select that which seems relevant and useful. Furthermore, Complex Problem Solving tasks usually require students to use - or at least consider - more than a single concept or principle or construct or idea.

Finally, there is usually more than one approach to a Complex Problem Solving task and a range of acceptable answers. Thus, part 
of the problem is to establish the criteria by which an acceptable answer is to be judged, to decide what kind of evidence or support is required, to gather the evidence, and to defend one's answer in light of the criteria established and the evidence available.

In short, Complex Problem Solving situations and problems resemble "real life" situations in their complexity, their ambiguity, and their structure.

The following questions illustrate Complex Problem Solving challenges.

A major publishing company has decided to publish a book on Hawthorne's short stories. Originally, the publishers planned to devote one whole section of the book to "Young Goodman Brown." They were going to ask several people to write articles on the story, each using a different approach to literary criticism. However, the publishers have now realized that they can't afford to devote so much space to "Young Goodman Brown." Instead, they want to include just one article analyzing "Young Goodman Brown," and they want the most illuminative and interesting analysis they can find. If you were going to submit such an analysis, what would you say about "Young Goodman Brown?"

The attached report summarizes a study conducted by Professor Wisdom investigating the effects of age on religious attitudes. Professor Wisdom has sent you this summary because he'd like your opinions about the research design, findings, and conclusions. Outline what you'd say in a response to Professor Wisdom.

Peter, who is mid-way through the first grade, is having a great deal of trouble with substraction, although he did fairly well with addition. He listens carefully when his teacher explains the material and tries hard to do the problems in his workbook. But he just can't seem to get it. Peter's teacher has asked you for advice, because she knows you are knowledgeable about several theories of child development and learning. Write her a letter outlining your recommendations and explaining which theory or theories prompted you to make those recommendations.

In the attached letter, a farmer describes an insect which appears to be making a pest of itself. As you'll discover, the farmer has provided a rather detailed description of his situation and has admitted that he's not altogether sure how much of the information is relevant. However, he'd like your advice on what to do about the insect. Prepare a response in which you recommend procedures for controlling the insect and explain why you recommend those procedures. 
Posted around the room are reproductions of 20 paintings. The art museum in your city wants to open an exhibit entitled "The Modern Tradition," and the museum has space for up to 15 of these paintings. The museum has asked for your advice about which paintings to include and how to organize them. What recommendations would you make and why?

\section{Writing Objectives for Complex Problem Solving}

It's difficult to write clear, concise objectives for Complex Problem Solving. On the one hand, the objectives should alert students to the complexity of the problems or situations which will be posed and should indicate the kinds of decisions which students will be asked to make. On the other hand, the objectives shouldn't be so lengthy or complicated that students get lost in the process of reading them. We think the following sample of objectives strike a reasonable compromise.

Be able to write an interesting and illuminating analysis of any American short story assigned. This will require you to consider the various approaches to literary analysis, to select the approach or combination of approaches which you think would produce the most interesting and illuminating analysis, and to carry out the analysis.

Be able to critique research on the effects of aging. This will require that you consider the questions under investigation, judge the appropriateness of the research design in light of the possibilities and constraints which the researcher faced, and determine whether or not the conclusions are warranted.

Given descriptions of children's responses in instructional situations, be able to explain their responses and recommend appropriate instructional activities. This will require you to study the situation presented, to consider the theories on development and learning which we've studied, to select the theory or combination of theories which best explain that particular situation, and to create instructional activities in light of your explanation.

Given information about an insect which is making a pest of itself in a certain environment, be able to recommend procedures for controlling the pest. This will require that you decide which features of the environment warrant attention, which characteristics of the insect are relevant, and which procedures for controlling the pest will be most effective, most practical, and most safe. 
Be able to organize or critique exhibitions of paintings in the Modern Tradition. This might require you to see possibilities and recognize limitations, given the paintings available; to determine whether such exhibitions should sample all modern art movements or concentrate on selected movements; to decide whether paintings should be organized historically, thematically or in some other fashion; to decide which paintings should be included and which excluded.

\section{Teaching for Complex Problem Solving?}

How people go about solving complex problems and how they learn to accomplish such feats remains pretty much a mystery. Research indicates that successful problem solvers approach and think through such problems in very different ways. Thus, we are not very taken with some of the current teaching methods and instructional materials which appear to prescribe problem solving steps and sequences.

Indeed, there's doubt about whether Complex Problem Solving abilities can be "taught" in the same sense that Memorization, Concept Formation and Application can be "taught". Gagne (1980) concludes his discussion of problem solving studies with considerable skepticism that we can design instruction which teaches the selecting and rejecting, weighing and choosing, structuring and restructuring abilities required for Complex Problem Solving. Instead, he suspects that these abilities develop from problem solving experience over a period of time and in a variety of situations. We share these suspicions and offer the following suggestions in light of them.

Provide opportunities for students to wrestle with Complex Problem Solving tasks and situations. If it's true that these abilities develop from experience over time and in a variety of situations, then perhaps professors can promote their development by providing a variety of experiences over time.

Encourage students to write things down as they read the problems. Successful problem solvers report that they jot down key ideas and information, note relationships, write themselves questions, draw diagrams and pictures. Such activities make sense as strategies for pulling out key ideas and restructuring situations. Often students 
merely read and reread problems, get lost in their complexities and give up when solutions don't emerge.

Stress that Complex Problem Solving often involves a lot of trial and error. More often than not, students see their professors discuss final versions of solutions or analyses - as if the solutions or analyses emerged in polished forms; as if the key ideas, questions and relationships were self evident; as if professors never felt confused, got stuck, pursued blind alleys, had to start over. If students expect that they should be able to produce a solution or an analysis after their first try, they're likely to become discouraged and give up the effort prematurely.

Be available to consult with students as they wrestle with complex problems and situations. There's considerable evidence in the research on student development indicating that many students will find such problems psychologically and emotionally distressing. It's not simply that the problems are difficult or that students lack competence or confidence. In far more fundamental and profound ways, these problems may challenge and disrupt students' views of knowledge, their ways of organizing experience and making sense of the world, their value systems, their relationships with parents, professors, and peers.

Knowing something about the ways in which students perceive these problems at different stages of development may not enable professors to help students solve such problems more successfully. However, the information may help professors "hear" what students are saying, understand why some students react in what appear bizarre or extreme ways, and provide insights about how to provide guidance and support.

\section{Testing for Complex Problem Solving}

Testing for Complex Problem Solving involves posing a particular problem or situation and asking students to do something with it - to solve the problem, to analyze the situation, to recommend policies, to make predictions, or whatever. However, descriptions of the requirements for evaluating these abilities are deceptively simple. 
Testing for Complex Problem Solving is a challenging task for professor as well as for students.

One part of the challenge to professors lies in finding or creating the problems or situations to be posed. They need to resemble "real life" situations in their complexity, their ambiguity and their structure, and often professors can find suitable situations by examining the issues and questions currently asked of or by scholars in their fields.

However, students are not yet scholars in these fields and it's probably not reasonable to expect them to cope with the same complexities. Thus, professors often find they must reshape or recast problems and must rely on experience to judge the level of complexity appropriate for their students.

Judgement is also required in "grading" students' performances on these tasks. Usually, tests of Complex Problems Solving are found in essay questions, paper assignments, or other types of projects, and it's difficult to ensure reliable and fair grading on such forms of evaluation. These difficulties are compounded by the fact that Complex Problem Solving situations usually can be approached in several ways and have a range of acceptable answers of bias ingrading students, performances on these tasks, there's no getting around the fact that judgement plays a prominent role in evaluating Complex Solving abilities.

\section{Selected Bibliography}

Anderson, Richard C., and Faust, Gerald W. Educational Psychology: The Science of Instruction and Learning. New York: Dodd, Mead and Company, 1973.

Chapter 10, "Concepts and Principles," includes a self-instructional program on information related to these two types of learning. The chapter also includes two interesting sections headed "On learning concepts and principles by discovering them."

Bloom, Benjamin S., Hastings, J. Thomas, and Madaus, George F. Handbook of Formative and Summative Evaluation of Student Learning. New York: McGraw-Hill Book Co., 1971.

Although this handbook focuses on how to design tests for various types of learning outcomes, each section begins with a description of the type of learning to be tested. The handbook also includes separate chapters suggesting alternative ways to conceptualize learning in art education (Chapter 17), in science (Chapter 18), in literature (Chapter 20), in a second language (Chapter 22). 
De Cecco, John P., and Crawford, William R. The Psychology of Learning and Instruction, second edition. Englewood Cliffs, New Jersey: Prentice-Hall, Inc., 1974.

The following chapters discuss different categories of learning and provide a relatively thorough discussion of the variables which influence each type of learning:

Chapter 8: Conditioning and Verbal Learning, pp. 202-244

Chapter 9: The Teaching and Learning of Psychomotor Skills, pp. 245-286.

Chapter 10: The Teaching and Learning of Concepts and Principles, pp. 287-323.

Chapter 11: Problem Solving, Creativity, and Discovery Learning, pp. 324-366.

Gagne, Robert M. The Conditions of Learning. New York: Holt, Rinehart and Winston, Inc., 1970.

This is, perhaps, Gagne's most thorough and readable discussion of the 8 types of intellectual skills: signal learning, stimulus-response learning, chaining, verbal associations, discrimination learning, concrete concept learning, defined concepts and rules, and problem solving.

Gagne, Robert M. and Briggs, Leslie J. Principles of Instructional Design. New York: Holt, Rinehart and Winston, Inc., 1974.

In Chapter 2, the authors propose that educational goals may be divided into five categories of learning: (1) intellectual skills; (2) cognitive strategies; (3) verbal information; (4) motor skills; and (5) attitudes. Chapter 3 outlines the conditions necessary for learning the 8varieties of intellectual skills and for learning cognitive strategies. Chapter 4 outlines the conditions for learning information, motor skills, and attitudes.

Gagne, Robert M. "Learnable Aspects of Problem Solving," Educational Psychologist, 1980, Vol. 15, No. 2, pp. 84-92.

Lembo, John M. The Psychology of Effective Classroom Instruction. Columbus, Ohio: Charles E. Merrill Publishing Company, 1969.

The following chapters are especially relevant:

Chapter 5: The Acquisition of Concepts, pp. 122-135.

Chapter 6: The Acquisition of Principles, pp. 136-153.

Chapter 7: Problem Solving and Creativity, pp. 154-169.

McDonald, Frederick J. Educational Psychology, second edition. Belmont, California: Wadsworth Publishing Company, Inc., 1965.

The following chapters are especially relevant:

Chapter 5: Learning and the Cognitive Processes: Concept Formation, pp. 160-199. 
Chapter 6: Learning and the Cognitive Processes: Generalizations and Associative Thinking, pp. 200-250.

Chapter 7: The Learning of Problem-Solving and Creative Behaviour, pp. 252-306.

Chapter 8: The Learning of Attitudes, pp. 307-341.

Chapter 9: The Leaming of Attitudes: Communication Processes, pp. 342-385.

Chapter 10: The Learning of Complex Performances, pp. 386-419.

Pelz, Donald D. "Environments for Creative Performance Within Universities" in Samuel Messick and Associates, Individuality in Learning. San Francisco: Jossey-Bass, Publishers, 1976, pp. 229-247.

Pelz reports some of his findings on the conditions required for creative problem solving and speculates on how university professors might nurture creativity. 